Received: 28 February 2017

Accepted: 27 July 2017

Published online: 30 August 2017

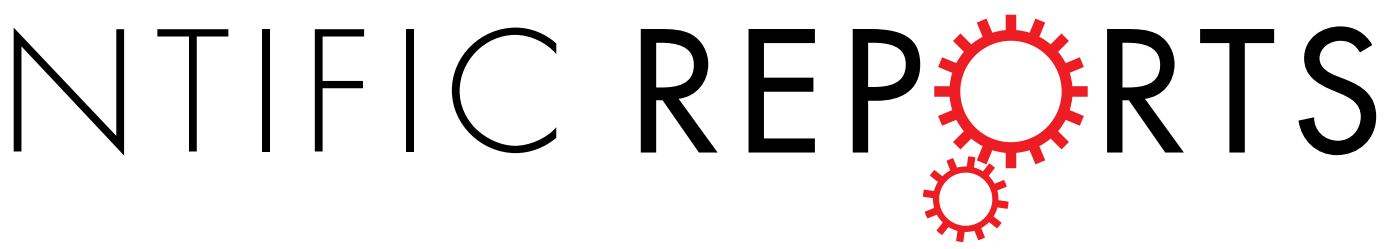

\title{
OPEN A Valuable Biochar from Poplar Catkins with High Adsorption Capacity for Both Organic Pollutants and Inorganic Heavy Metal lons
}

\author{
Xia Liu ${ }^{1,2}$, Ju Sun ${ }^{1,2}$, Shengxia Duan ${ }^{1,2}$, Yanan Wang ${ }^{1,2}$, Tasawar Hayat ${ }^{4}$, Ahmed Alsaedi ${ }^{4,5}$, \\ Chengming Wang ${ }^{2}$ \& Jiaxing $\mathrm{Li}^{1,3,4}$
}

In this paper, biochar derived from poplar catkins was used as an economical and renewable adsorbent for adsorption organic and inorganic pollutants such as, dyes, organic compounds, and heavy metal ions from wastewater. Mesoporous activated carbonized poplar catkins (ACPCs) were produced from char as a by-product by carbonized poplar catkins (CPCs). With their high surface area, ACPCs exhibited the maximum adsorption capacities of 71.85 and $110.17 \mathrm{mg} / \mathrm{g}$ for the removal of inorganic $\mathrm{U}(\mathrm{VI})$ and $\mathrm{Co}(\mathrm{II})$. Compared other biochars adsorbents, ACPCs can also adsorb organic pollutants with the maximum adsorption capacities of 534, 154, 350, 148 and $384 \mathrm{mg} / \mathrm{g}$ for methylene blue (MB), methyl orange (MO), Congo red (CR), chloramphenicol (CAP) and naphthalene. The adsorption of organic pollutants was fitted with pseudo-first order, pseudo-second order, and intra-particle diffusion kinetic models figure out the kinetic parameters and adsorption mechanisms. Langmuir adsorption isotherm was found to be suitable for $\mathrm{Co}(\mathrm{II})$ and $\mathrm{U}(\mathrm{VI})$ adsorption and thermodynamic studies indicated adsorption processes to be endothermic and spontaneous. The adsorption process includes both outer-sphere surface complexes and hydrogen-bonding interactions. The results showed that biochar derived from poplar catkins was a potential material to remove pollutants in wastewater.

Water pollution by organic compounds such as polycyclic aromatic hydrocarbon (PAHs), pesticides, antibiotics and dyes and inorganic heavy metal ions, has been causing considerable worldwide concern ${ }^{1-3}$. Organic pollutants and heavy metal ions management attracts more and more attention of people, because these pollutants are high mobility and long persistence in the environment ${ }^{4-6}$. Therefore, it is significant important to develop an efficient and economical strategy for removal of pollutants in waste water ${ }^{6-8}$.

A number of effective techniques including adsorption, filtration and ion exchange, have been applied to remove inorganic and organic pollutants from waste solutions ${ }^{9-11}$. Among these techniques, adsorption has become one of the most widely used techniques for water pollution management due to its outstanding characteristics, such as low cost, wide adaptability, and convenience ${ }^{12}$. In the past decades, activated carbon has been used to remove pollutants from wastewater but with low regeneration efficiency, which inspire researchers to search for new alternatives with high efficiencies ${ }^{12-14}$. In the quest for economic and effective adsorbents, biomass has been evaluated with variable degree of sources ${ }^{15}$, 16 . Low-cost banana and orange peels were carbonized to biochar for removal of dyes from wastewater in Gurusamy Annadurai's work ${ }^{17}$. Huang et al. successfully synthesized biomass adsorbent through the pyrolysis of kapok wadding materials for efficiently solving organic pollution ${ }^{18}$. Physic-chemical characteristics and the adsorption capacity for methylene blue of rice hull ash were

${ }^{1}$ Institute of Plasma Physics, Chinese Academy of Sciences, P.O. Box 1126, Hefei, 230031, P.R. China. ${ }^{2}$ University of Science and Technology of China, Hefei, 230026, P.R. China. ${ }^{3}$ Collaborative Innovation Center of Radiation Medicine of Jiangsu Higher Education Institutions, Suzhou, P.R. China. ${ }^{4}$ NAAM Research Group, Faculty of Science, King Abdulaziz University, Jeddah, 21589, Saudi Arabia. ${ }^{5}$ Department of Mathematics, Quaid-I-Azam University, Islamabad, 44000, Pakistan. Correspondence and requests for materials should be addressed to J.L. (email: lijx@ipp.ac.cn) 

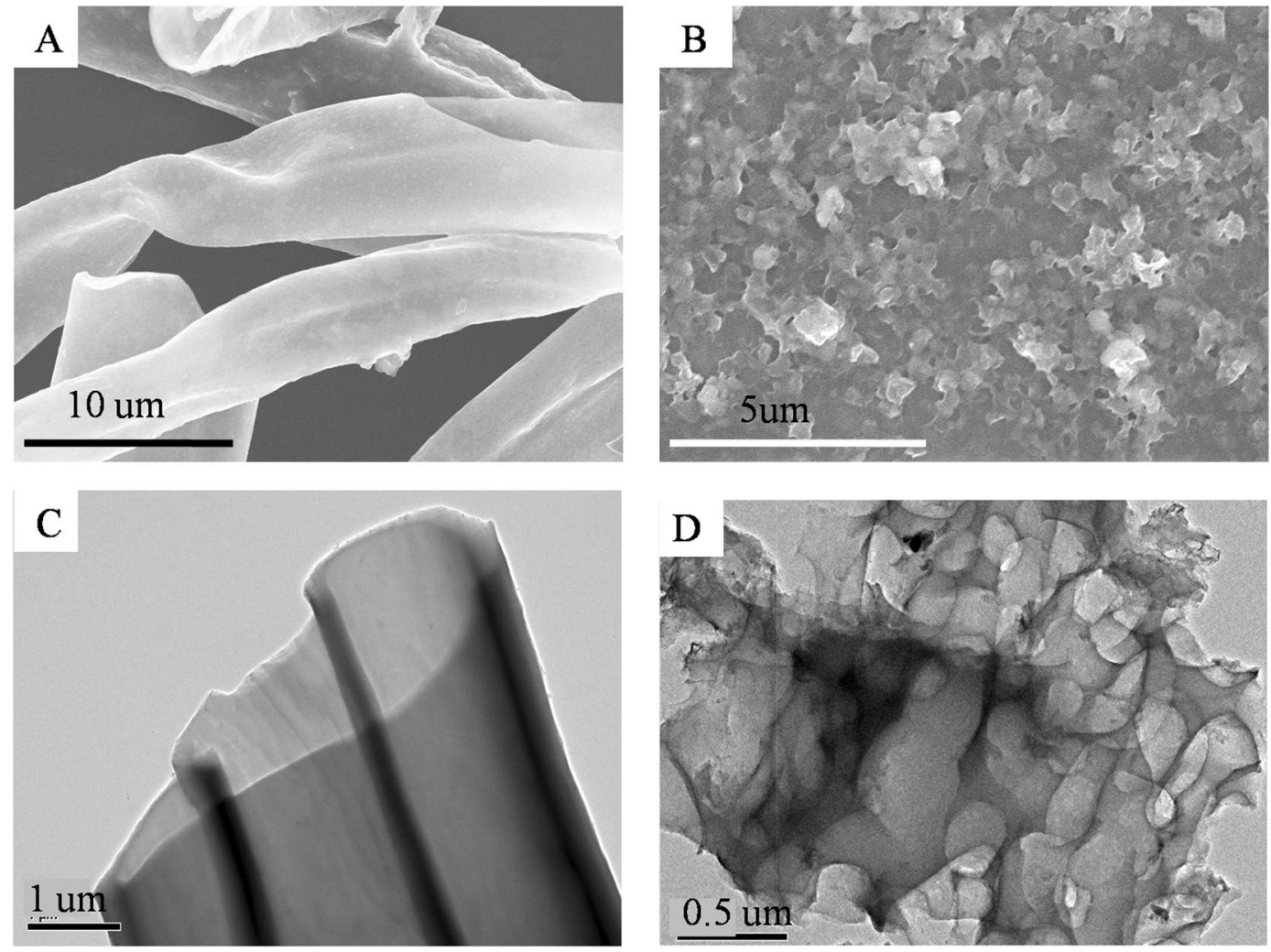

Figure 1. SEM images for CPCs (A) and ACPCs (B) TEM for CPCs (C) and ACPCs (D).

systematically studied ${ }^{19}$. Although these biomasses are cheaper than other absorbents, it still suffers some problems, such as remaining economic value, poor adsorption performance and so on.

Poplar alba as a kind of deciduous tree is universally planted in China ${ }^{20}$. Poplar catkins are lightweight and fly around everywhere in summer season. Nevertheless, the flying poplar catkins are harmful for human body in lots of respects, such as promoting runny nose, affecting respiratory system. Moreover, they can cause skin irritation and insomnia ${ }^{21}$. Therefore, it is essential to develop an economically technology for utilizing poplar catkins in large scale. Many reports have been focused on dealing with this problem ${ }^{20-23}$. Though the poplar catkins can be used as biochar, rarely studied has been focused on its application on heavy metal ion and organic pollution.

In this study, carbon micro-tube and mesoporous activated samples were prepared by carbonizing the poplar catkin. The as-prepared samples activated carbonized poplar catkins (ACPCs) and carbonized poplar catkins (CPCs) were characterized by scanning electron microscopy (SEM), transmission electron microscopy (TEM), Fourier transform infrared (FT-IR) spectroscopy, X-ray photoelectron spectroscopy (XPS), BrunauerEmmett-Teller (BET)- $\mathrm{N}_{2}$ surface area and the powder X-ray diffraction analysis (XRD). Besides, the elemental composition was characterized, including $\mathrm{C}, \mathrm{H}, \mathrm{O}$, and $\mathrm{N}$. The products were then applied adsorption by batch experiments. The possible adsorption mechanism of the pollutants was investigated through FT-IR analysis.

\section{Results and Discussion}

Characterization of CPCs and ACPCs. The morphologies of CPCs and ACPCs were characterized by using SEM and TEM analysis. The CPCs samples showed hollow micro-tubular structure with the thin layers ${ }^{24,25}$ (Fig. 1A) while the SEM image of ACPCs (Fig. 1B) displayed a network and porous structure stacked by irregular flakes, which could be considered as high specific surface area. The TEM image of CPCs (Fig. 1C) confirmed its hollow micro-tubular structure while ACPCs (Fig. 1D) were network structure stacked by irregular flakes. The structure of ACPCs facilitated the rapid adsorption process by accelerating the transportation of the pollutants from the outer surface into the inner porous network ${ }^{25}$.

XRD patterns of the CPCs and the ACPCs were shown in Fig. 2A. The as-prepared ACPCs displayed a broad feature at $24^{\circ}$ and a weak one at $43^{\circ}$, corresponding to the (002) and (101) planes, respectively, demonstrating amorphous structures. As compared with ACPCs, the peak at $43^{\circ}$ was weaker in CPCs, indicating a lower degree of interlayer condensation in CPCs ${ }^{26-29}$. The XPS results of CPCs and ACPCs applying to detect the surface states were shown in Fig. 2B. Strong C 1s peaks were observed in both spectra, indicating dominant carbon element in both adsorbents. However, the ratio of $\mathrm{C} / \mathrm{O}$ increased from 3.67 to 7.73 for CPCs and ACPCs, indicating an increased oxygen degree after $\mathrm{KOH}$ treatment ${ }^{29}$. The $\mathrm{C} 1$ s peaks of CPCs (Fig. 2C) and ACPCs (Fig. 2D) were further resolved into five peaks, i.e. C-C, C-OH, C-O-C, $\mathrm{C}=\mathrm{O}$, and $\mathrm{C}-\mathrm{OOH}$ with binding energies of 284.5, 286.2, $287.1,288.0$, and $289.5 \mathrm{eV}$, respectively ${ }^{30}$. The elemental composition, including $\mathrm{C}, \mathrm{H}, \mathrm{O}$, and $\mathrm{N}$, are shown in 

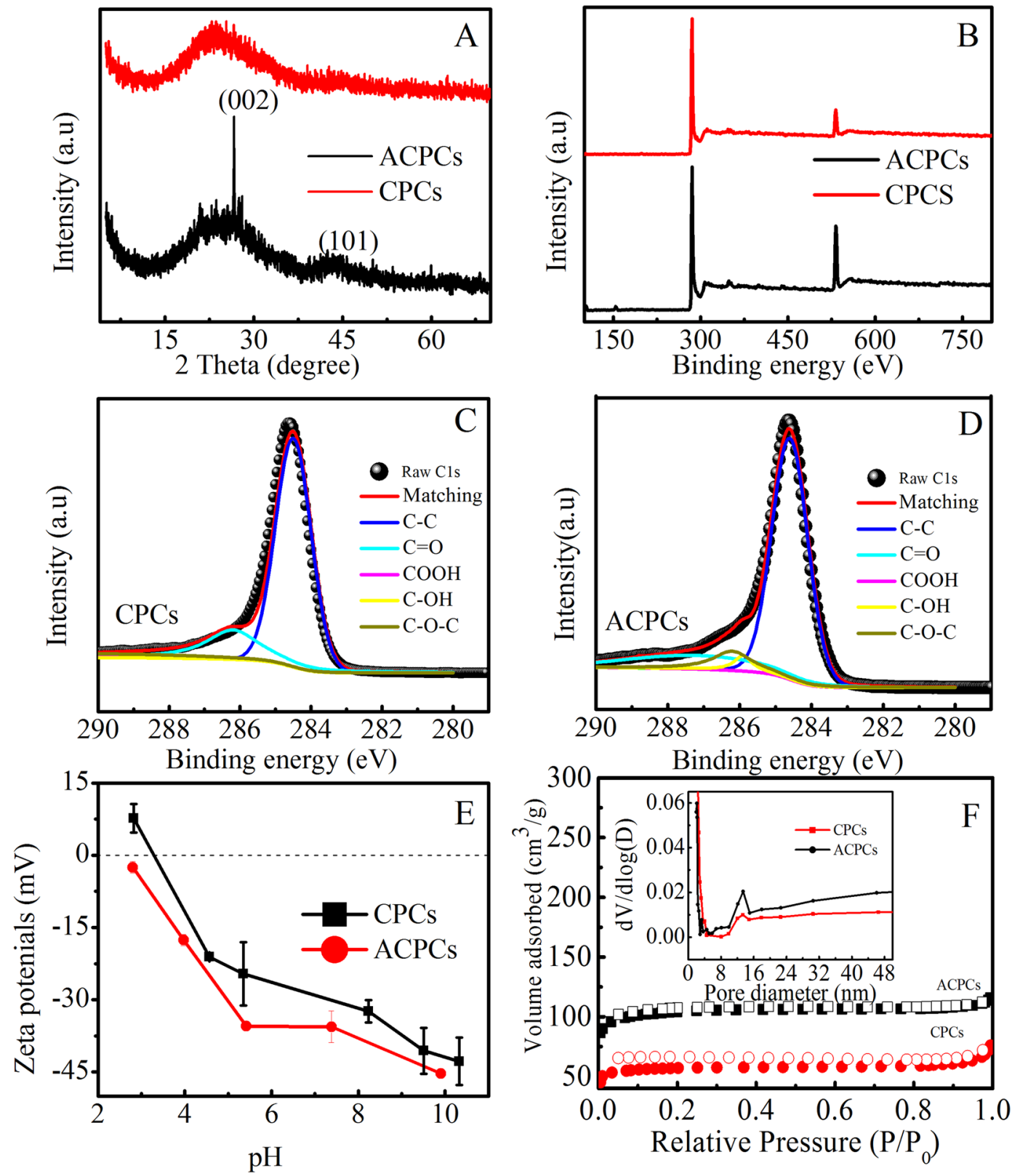

Figure 2. XRD patterns of CPCs and ACPCs (A) XPS spectrums of CPCs and ACPCs. (B) C1s XPS spectrums of CPCs (C) and ACPCs (D) Zeta potentials of CPCs and ACPCs at various $\mathrm{pH}$ values (E) Nitrogen adsorptiondesorption isotherms of CPCs and ACPCs (F).

Table S1. The relative amount of C element decreased from about $64 \%$ to $58 \%$ after $\mathrm{KOH}$ treatment, suggesting an increased oxygen degree after $\mathrm{KOH}$ treatment.

Zeta potentials were used to analyze surface properties of CPCs and ACPCs in aqueous solution (Fig. 2E). The $\mathrm{pH}_{\mathrm{pzc}}$ values (point zero of charge) of CPCs and ACPCs, mainly determined by its chemical nature ${ }^{31}$, were estimated to be 3.5 and 3.0, respectively. ACPCs had a much lower zeta potential than CPCs, suggesting a more negatively charged surface of ACPCs in water than that of CPCs, which can be caused by oxygen-abundant functional groups on the surface of ACPCs ${ }^{32}$. The more negatively charged surface led to adsorb positively charged pollutant more easily and more oxygen-abundant functional groups resulted in chemisorptions more obvious ${ }^{33}$. The BET surface area, an important influencing factor for adsorption capacity, gave values on the specific surface area and pore structure of ACPCs and CPCs. Figure $2 \mathrm{~F}$ was obtained from $\mathrm{N}_{2}$ adsorption-desorption isotherm measurements. The larger surface areas (351.4 and $191.1 \mathrm{~m}^{2} / \mathrm{g}$ for ACPCs and CPCs) and slightly smaller average pore diameter ( 2.15 and $1.96 \mathrm{~nm}$ for CPCs and ACPCs) was achieved, indicating better development of the porosity after $\mathrm{KOH}$ activation. These values were also higher than many reported biochars as listed in Table S2.

Adsorption study. Organic dyes adsorption. The adsorption capacities of ACPCs and CPCs with positively charged methylene blue (MB), negatively charged methyl orange (MO) and neutral Congo red (CR) were studied 

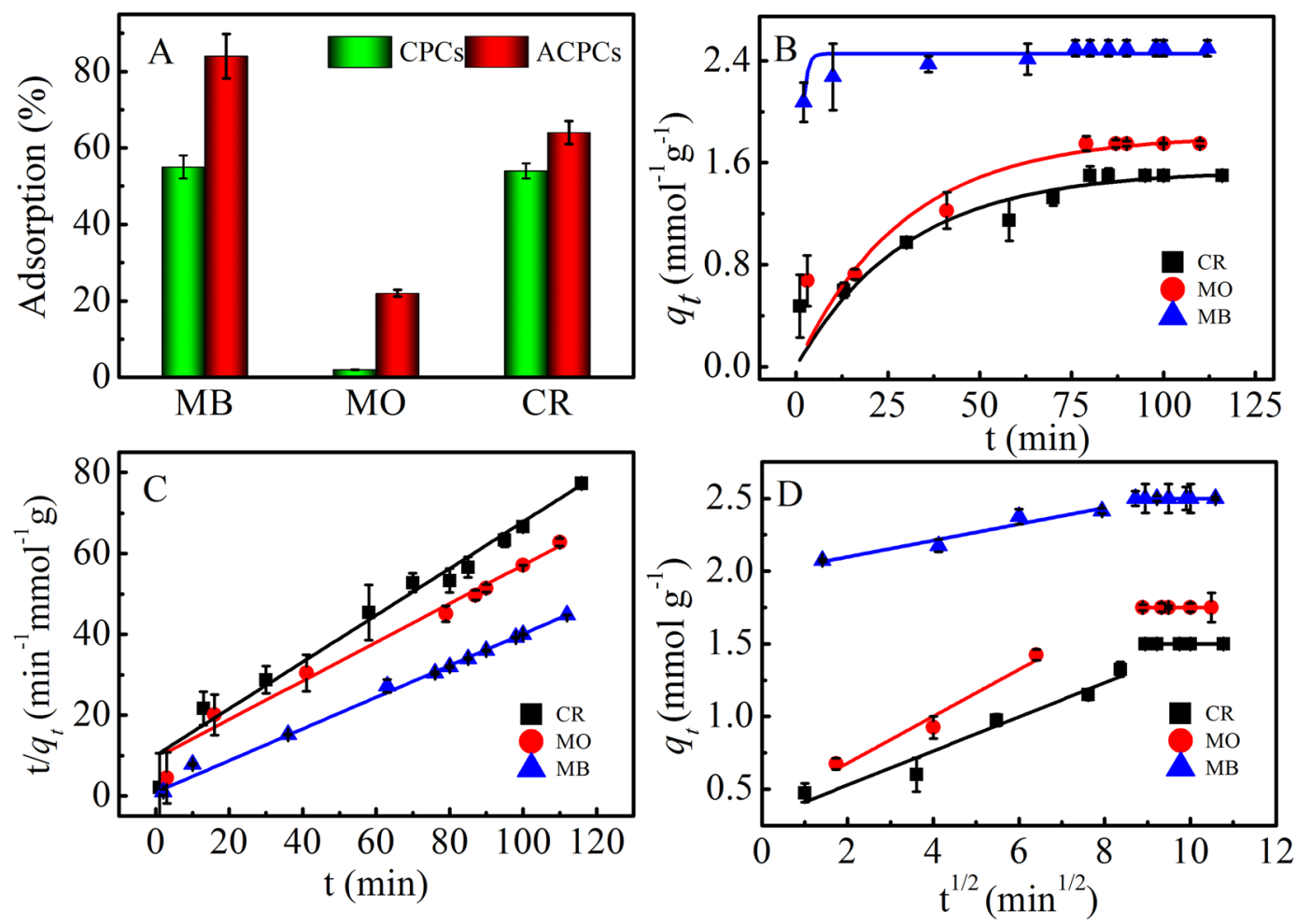

Figure 3. Adsorption capacities toward MB, MO and CR of ACPCs and CPCs (A) pseudo-first-order (B) pseudo-second-order (C) intraparticle diffusion (D) $\mathrm{C}_{0}=0.016 \mathrm{mM}, \mathrm{m} / \mathrm{V}=0.04 \mathrm{~g} \mathrm{~L}^{-1}, \mathrm{~T}=303 \mathrm{~K}, \mathrm{pH}=6.0$.

and depicted in Fig. 3A. ACPCs exhibited the highest adsorption capacity toward MB, which is 1.5 times higher than that of CPCs. The adsorption capacity was got from adsorption isotherms shown in Figure S1. The adsorption performances (\%) of ACPCs toward MO and CR were 14 and 22\%, which 10 times and 1.2 times than that of CPCs. By comparing the adsorption data, the adsorption capacity toward MB was better than both MO and $\mathrm{CR}$, which could be ascribed to the negative zeta potentials of ACPCs and CPCs ${ }^{33,34}$. MB surface was positively charged, MO was negatively charged and while CR was neutral. Therefore, the electrostatic attraction force for $\mathrm{MB}$ was stronger than $\mathrm{MO}$ and CR. The adsorption performances of ACPCs toward organic dyes (MB, MO and $\mathrm{CR}$ ) were better than CPCs, which attributed to oxygen-containing functional groups and their surface areas. The results were consistent with many reports ${ }^{2,7,8,31,35}$. For example, active carbon displayed much higher adsorption capacity toward $\mathrm{MB}$ than graphene oxide and carbon nanotubes which was related with its highest surface area in Li's work ${ }^{35}$. Chen et al. reported that cotton derived porous carbon oxide possessed the advantage of a higher adsorption capacity than cotton derived porous carbon, which confirmed that oxygen-containing functional groups could enhance adsorption ${ }^{31}$. Table 1 presented comparative adsorption capacities of reported biochars. Adsorption capacities of ACPCs were higher than many other biochars. Thus, the comparison of adsorption capacities showed that ACPCs was an efficient adsorbent for the uptake of dyes. It was worth noting that there was still some biochars having higher adsorption capacity than ACPCs, whose functional groups could greatly enhance adsorption capacity.

Adsorption kinetics, an important adsorbent design factor, can directly reflect the sorbent uptake rate. In this study, the adsorption kinetics were conducted with the sample concentration of $0.04 \mathrm{~g} \cdot \mathrm{L}^{-1}$ at $303 \mathrm{~K}$. Three kinetic models were used to analyze the mechanism of the adsorption process, i.e. pseudo-first order model (Fig. 3B), pseudo-second order model (Fig. 3C), and intra-diffusion (Fig. 3D) and the related parameters are in Table 2.

The pseudo first-order equation describes adsorption in solid-liquid systems. It expressed as following ${ }^{36-38}$ :

$$
\log \left(q_{e}-q_{t}\right)=\log q_{e}-\frac{k_{1}}{2.303} t
$$

where $q_{e}$ and $q_{t}\left(\mathrm{mmol} \mathrm{g}^{-1}\right)$ are the adsorption capacities at equilibrium and at time $t$ ( $\left.\mathrm{min}\right)$, respectively.

The pseudo second-order rate expression, which was applied for analyzing chemisorption kinetics from liquid solutions, was linearly expressed as $^{39}$ :

$$
\frac{\mathrm{t}}{q_{t}}=\frac{1}{k_{2} q_{e}^{2}}+\frac{1}{q_{e}} t
$$

where $k_{2}$ is the rate constant for pseudo second-order adsorption $\left(\mathrm{g} \mathrm{mmol}^{-1} \mathrm{~min}^{-1}\right)$.

By comparing the correlation coefficients $\left(\mathrm{R}^{2}\right)$, pseudo-second order kinetic model (0.995-0.998) exhibited much higher correlation coefficients than pseudo-first order kinetic model (0.85-0.89), demonstrating a 


\begin{tabular}{|c|c|c|c|}
\hline Adsorbents & Adsorbed substances & $q_{e}(\mathrm{mg} / \mathrm{g})$ & Ref \\
\hline Banana peel & MO & 21 & 36 \\
\hline Tobacco stem ash & $\mathrm{MB}$ & 35.7 & 49 \\
\hline Banana peel & CR & 18.2 & 36 \\
\hline Orange peel & $\mathrm{MO}$ & 20.5 & 36 \\
\hline Orange peel & $\mathrm{MB}$ & 18.6 & 36 \\
\hline Orange peel & CR & 14.3 & 36 \\
\hline Apricot shell & MB & 4.11 & 49 \\
\hline wheat straw & MO & 278.7 & 50 \\
\hline Rice husk & $\mathrm{MB}$ & 578 & 2 \\
\hline waste polystyrene & CR & 500 & 51 \\
\hline \multirow{3}{*}{ Poplar catkins } & $\mathrm{MB}$ & 534 & \multirow{3}{*}{ This work } \\
\hline & MO & 154 & \\
\hline & $\mathrm{CR}$ & 350 & \\
\hline Bamboo charcoal & CAP & 8.1 & 56 \\
\hline Crop residue & CAP & 742.4 & 57 \\
\hline Bean pods & naphthalene & 300 & 58 \\
\hline Orange peels & naphthalene & 80.6 & 1 \\
\hline \multirow{2}{*}{ Poplar catkins } & CAP & 148 & \multirow{2}{*}{ This work } \\
\hline & naphthalene & 384 & \\
\hline Penicillium citrinum & $\mathrm{U}(\mathrm{VI})$ & 255.1 & 59 \\
\hline Rice husk & $\mathrm{Co}(\mathrm{II})$ & 45.2 & 60 \\
\hline Almond shell & $\mathrm{U}(\mathrm{VI})$ & 28.09 & 61 \\
\hline Seaweeds & $\mathrm{Co}(\mathrm{II})$ & 18.58 & 62 \\
\hline \multirow{2}{*}{ Poplar catkins } & $\mathrm{U}(\mathrm{VI})$ & 71.85 & \multirow{2}{*}{ This work } \\
\hline & $\mathrm{Co}(\mathrm{II})$ & 110.17 & \\
\hline
\end{tabular}

Table 1. Comparison of various adsorbent materials.

\begin{tabular}{|l|l|l|l|l|l|l|}
\hline Adsorbate & \multicolumn{2}{l|}{ pseudo-first-order } & \multicolumn{2}{l|}{ pseudo-second-order } & \multicolumn{2}{l|}{ Intra-diffusion model } \\
\hline \multirow{4}{*}{$\mathrm{MB}$} & $\mathrm{k}_{1}$ & 0.033 & $\mathrm{k}_{2}$ & 0.015 & $\mathrm{k}_{3}$ & 0.079 \\
\cline { 2 - 7 } & $q_{e}$ & 0.409 & $q_{e}$ & 0.42 & $\mathrm{C}_{3}$ & 0.33 \\
\cline { 2 - 8 } & $\mathrm{R}^{2}$ & 0.85 & $\mathrm{R}^{2}$ & 0.998 & $\mathrm{R}^{2}$ & 0.96 \\
\hline \multirow{4}{*}{$\mathrm{MO}$} & $\mathrm{k}_{1}$ & 0.95 & $\mathrm{k}_{2}$ & 0.024 & $\mathrm{k}_{3}$ & 0.115 \\
\cline { 2 - 8 } & $q_{e}$ & 0.302 & $q_{e}$ & 0.35 & $\mathrm{C}_{3}$ & 0.29 \\
\cline { 2 - 8 } & $\mathrm{R}^{2}$ & 0.88 & $\mathrm{R}^{2}$ & 0.995 & $\mathrm{R}^{2}$ & 0.98 \\
\hline \multirow{3}{*}{$\mathrm{CR}$} & $\mathrm{k}_{1}$ & 0.033 & $\mathrm{k}_{2}$ & 0.36 & $\mathrm{k}_{3}$ & 0.012 \\
\cline { 2 - 7 } & $q_{e}$ & 0.256 & $q_{e}$ & 0.29 & $\mathrm{C}_{3}$ & 0.25 \\
\cline { 2 - 7 } & $\mathrm{R}^{2}$ & 0.89 & $\mathrm{R}^{2}$ & 0.997 & $\mathrm{R}^{2}$ & 0.97 \\
\hline
\end{tabular}

Table 2. Parameters for Kinetics Models for the Adsorption of MB, MO, and CR.

pseudo-second order kinetic model for the adsorption of $\mathrm{MB}, \mathrm{MO}$, and CR onto ACPCs. However, the investigation of diffusion mechanisms and rate controlling procedure were beyond the scope of pseudo-first and pseudo-second order kinetic models, intra-particle diffusion model was applied for further investigation.

Intraparticle diffusion focuses on the adsorbate transportation from external surface to pores and the rate-controlling adsorption process, respectively. The model could be expressed as ${ }^{40}$ :

$$
q_{t}=k_{i} t^{1 / 2}+C
$$

where $\mathrm{k}_{\mathrm{i}}$ is the diffusion rate constant and $\mathrm{C}$ is a constant.

As shown in Fig. 3D, the plot of $\mathrm{q}_{\mathrm{t}}$ against $\mathrm{t}^{1 / 2}$ includes two linear sections, which correspond to a two-step adsorption process. The first linear line indicated the diffusion of dyes from solutions to the surfaces of ACPCs, followed by a slow diffusion of dyes into pores. The second linear section with a smaller slope indicated the final equilibrium stage where the intra-particle diffusion started to slow down and to reach the final equilibrium status.

Chloramphenicol (CAP) and naphthalene adsorption. Figure 4A depicted adsorption capacity of $30 \mathrm{mg} \mathrm{L}^{-1}$ of CAP and naphthalene, respectively by $0.04 \mathrm{~g} \mathrm{~L}^{-1}$ of ACPCs and CPCs for 12 hours at $\mathrm{pH}$ 7.0. A higher adsorption capacity of ACPCs than CPCs for organic pollutant can be found. The results of the CAP and 

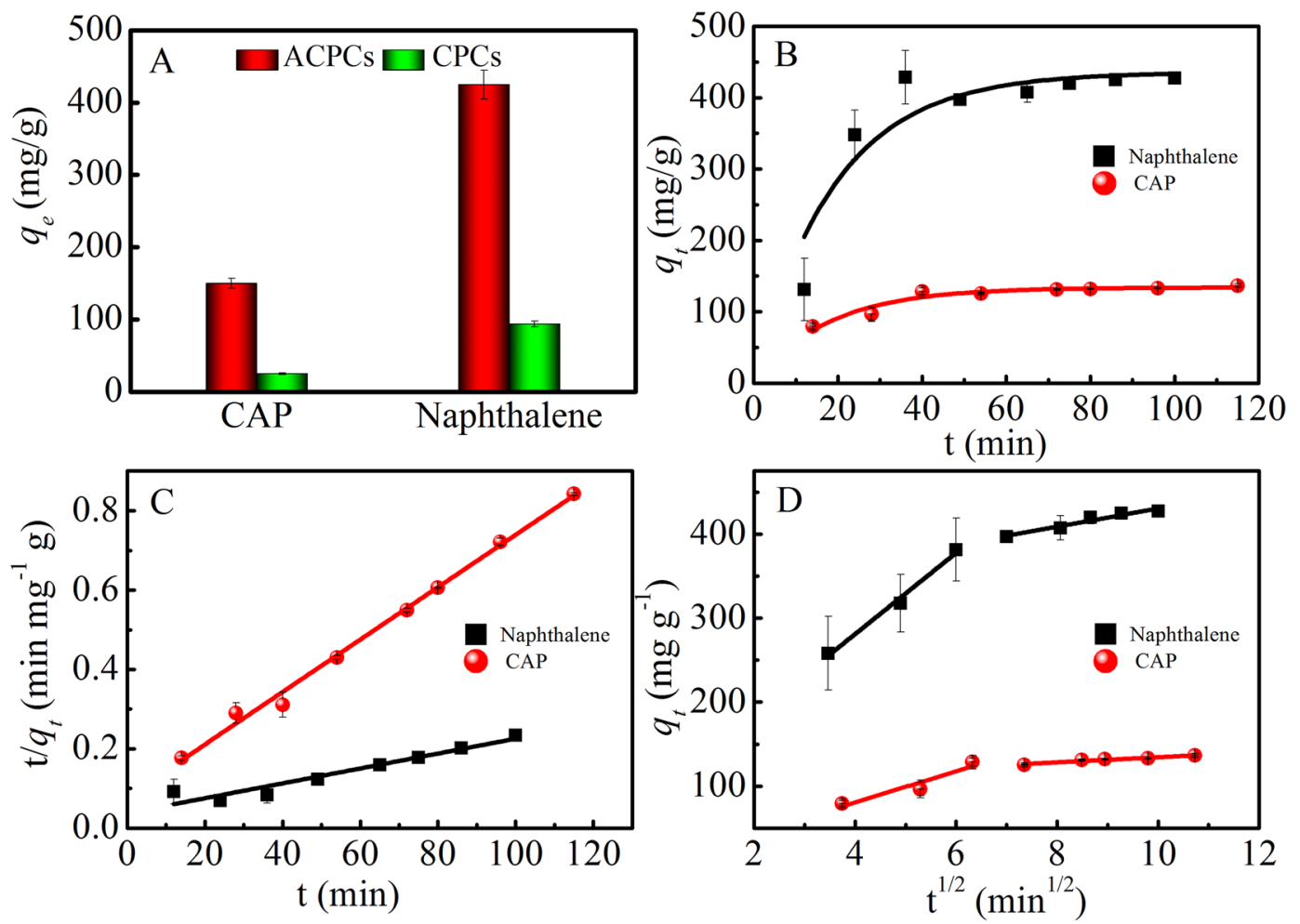

Figure 4. Adsorption capacities toward CAP and naphthalene of ACPCs and CPCs (A) pseudo-first-order (B) pseudo-second-order (C) intraparticle diffusion (D) $\mathrm{C}_{0}=30 \mathrm{mg} / \mathrm{L}, \mathrm{m} / \mathrm{V}=0.04 \mathrm{~g} \mathrm{~L}^{-1}, \mathrm{~T}=303 \mathrm{~K}, \mathrm{pH}=7.0$, $\mathrm{I}=0.01 \mathrm{~mol} \mathrm{~L}^{-1} \mathrm{NaNO}_{3}$.

naphthalene kinetics data fitted to the various theoretical models were shown on Fig. 4B-D. The corresponding kinetic parameters calculated from the different equations are compiled in Table S3. Pseudo-first-order and intra-particles models suggested that they may not be suitable to describe the kinetics of naphthalene adsorption on ACPCs. On the contrary, $\mathrm{R}^{2}$ of the pseudo-second-order model is higher than other two models, which indicated that the pseudo-second order kinetic model can be can well describe the adsorption process ${ }^{41,42}$.

Heavy metal ions adsorption. The adsorption capacities of ACPCs toward inorganic Co(II) and U(VI) were also investigated. The adsorption of $\mathrm{Co}$ (II) on the ACPCs was highly dependent on $\mathrm{pH}$ (Fig. 5A). The $\mathrm{Co}$ (II) adsorption on ACPCs increased slowly at $\mathrm{pH} 2.0$ to 5.0, then increased sharply within $\mathrm{pH} 5.0$ to 10.0 , and reached the maximum at $\mathrm{pH}>10.0^{43}$. This phenomenon may be contributed to the electrostatic attraction between $\mathrm{Co}$ (II) and $\mathrm{ACPCs}^{43}, 44$. Cobalt existed in the form of $\mathrm{Co}^{2+}, \mathrm{Co}(\mathrm{OH})^{+}, \mathrm{Co}(\mathrm{OH})_{2}$, and $\mathrm{Co}(\mathrm{OH})_{3}{ }^{-}$at different $\mathrm{pH}$ values (Figure S2A). Low adsorption efficiency of $\mathrm{Co}(\mathrm{II})$ at $\mathrm{pH}<5.0$ on ACPCs was ascribed to the competition with $\mathrm{H}^{+}$ions for the binding sites onto ACPCs ${ }^{45}$, 46. The surface deprotonation reaction at high $\mathrm{pH}$ values resulted in deprotonated sites increased with increasing $\mathrm{pH}$. The deprotonated sites were easier to keep the $\mathrm{Co}(\mathrm{II})$ ions, and surface complexation between $\mathrm{Co}^{2+}, \mathrm{Co}(\mathrm{OH})^{+}$, and ACPCs is strengthen, thus the $\mathrm{Co}(\mathrm{II})$ adsorption capacity increase sharply at $\mathrm{pH} 6.0-8.5$ and $\mathrm{Co}(\mathrm{OH})_{2}$ precipitation begins to form at $\mathrm{pH}>8.5$.

The influence of ionic strength toward $\mathrm{Co}(\mathrm{II})$ adsorption was also examined within the tested $\mathrm{pH}$ ranges (Fig. 5A). The ionic strength affected the thickness of the double layer, and resulted the binding ability towards the adsorbing species ${ }^{47}$. The ionic strength-dependent adsorption capacity suggested that electrostatic outer-sphere complexation reactions might be a sorption mechanism for $\mathrm{Co}(\mathrm{II})$ adsorption.

As shown in Fig. 5B, the adsorption of U(VI) on ACPCs surface increased with increasing pH from 2.5 to 5.0 , then reached a maximum adsorption capacity of about $20 \mathrm{mg} / \mathrm{g}$ at $\mathrm{pH} 6.0$, while decreased adsorption was observed at $\mathrm{pH}>6.5$. The species distribution of $\mathrm{U}(\mathrm{VI})$ at different $\mathrm{pH}$ values can be used to explain the observed adsorption tendency as shown in Figure S2B. The major species of $\mathrm{U}(\mathrm{VI})$ in aqueous was $\mathrm{UO}_{2}{ }^{2+}$ at $\mathrm{pH}<5.0$, and more multiple positive charged $\mathrm{U}(\mathrm{VI})$ species were observed at $\mathrm{pH}$ 5.0-8.0, whereas the negative charged U(VI) species were observed at $\mathrm{pH}>8.0^{45}$, 47 . Influence of ionic strength on the adsorption of U(VI) was studied in different $\mathrm{NaNO}_{3}$ solutions. It can be seen that ionic strength has major effect on the U(VI) adsorption, suggesting that an outer-sphere surface complexation dominant adsorption process ${ }^{48,49}$.

Adsorption Isotherms. The adsorption isotherms for Co(II) and U(VI) obtained at 303, 313, and $323 \mathrm{~K}$ were shown in Fig. 5C and D. To have a better understanding of the mechanism and to quantify the adsorption data, Langmuir and Freundlich isotherm models were conducted to simulate the adsorption. The Langmuir isotherm model $\left(q_{e}=\frac{b q_{\max } C_{e}}{1+b C_{e}}\right)$ describes monolayer adsorption process ${ }^{50,51} \cdot q_{\max }(\mathrm{mg} / \mathrm{g})$ represented the maximum 

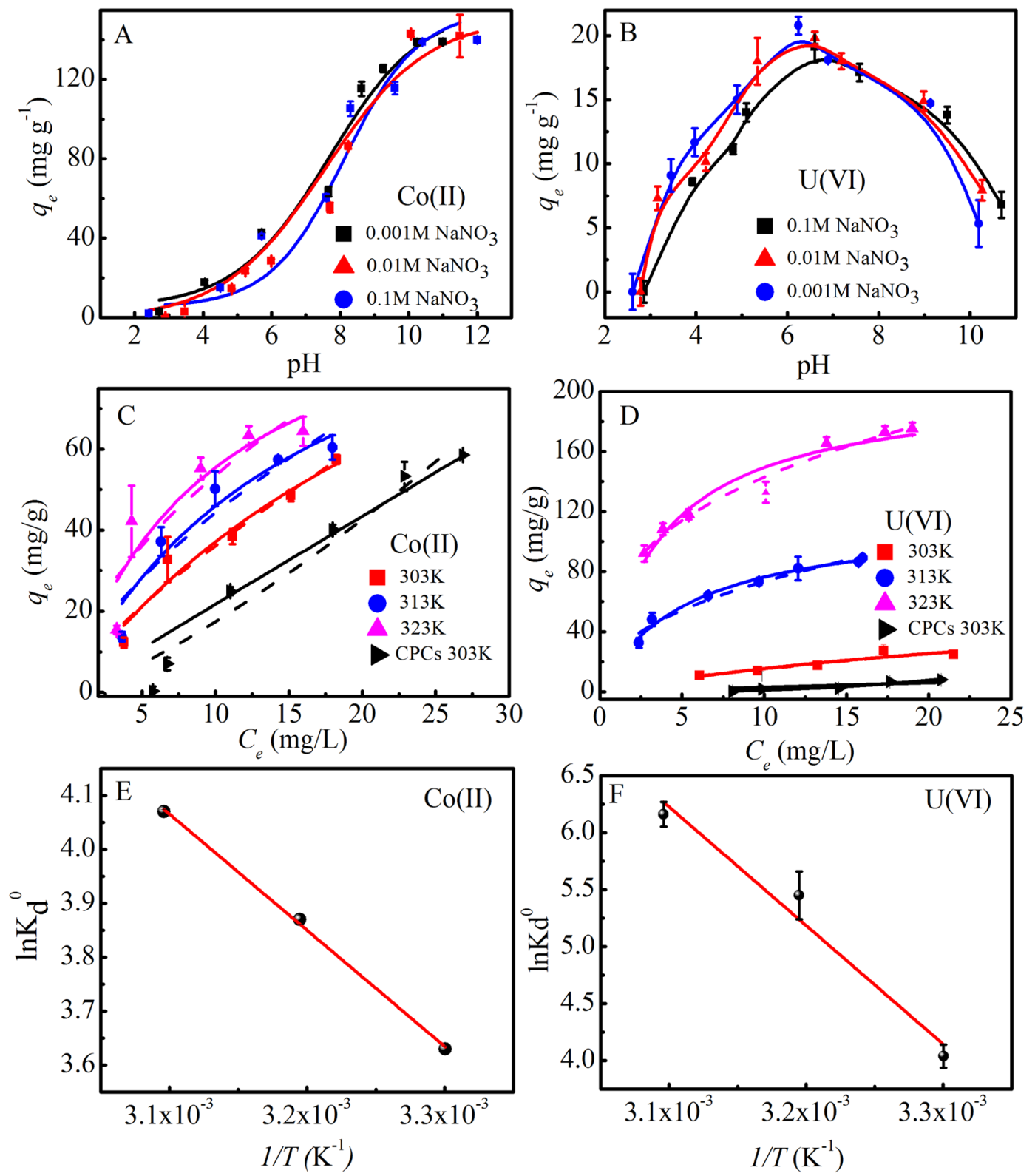

Figure 5. Effect of $\mathrm{pH}$ and ionic strength on the adsorption of (A) $\mathrm{Co}(\mathrm{II})$ and (B) U(VI) onto ACPCs; Adsorption isotherms of $\mathrm{Co}(\mathrm{II})$ and $\mathrm{U}(\mathrm{VI})$ on ACPCs at different temperatures and CPCs at $303 \mathrm{~K}$. Co(II): $\mathrm{pH}=6.0, \mathrm{~m} / \mathrm{V}=0.1 \mathrm{gL}^{-1}, \mathrm{I}=0.01 \mathrm{molL}^{-1} \mathrm{NaNO}_{3}(\mathrm{C}) \mathrm{U}(\mathrm{VI}): \mathrm{pH}=5.0, \mathrm{~m} / \mathrm{V}=0.1 \mathrm{gL}^{-1}, \mathrm{I}=0.01 \mathrm{~mol} \mathrm{~L}^{-1}$ $\mathrm{NaNO}_{3}(\mathbf{D})$ Plots of $\operatorname{lnk}_{\mathrm{d}}{ }^{0}$ vs. $1 / \mathrm{T}$ for $\mathrm{Co}(\mathrm{II})$ adsorption $(\mathbf{E})$ and for U(VI) adsorption (F) on ACPCs $\mathrm{C}_{0}=15.0 \mathrm{mg} \mathrm{L}^{-1}, \mathrm{~m} / \mathrm{V}=0.1 \mathrm{gL}^{-1}, \mathrm{~T}=303 \mathrm{~K}$.

adsorption capacity, and $\mathrm{b}(\mathrm{L} / \mathrm{mg})$ is the constant that corresponds to the heat of adsorption. The Freundlich isotherm model, which allowed for several kinds of adsorption sites on the solid, can be represented by the equation $\left(\mathrm{q}_{e}=K_{F} C_{e}^{n}\right)^{52}$, where $K_{F}\left(\mathrm{mg}^{1-n} \mathrm{~L}^{\mathrm{n}} / \mathrm{g}\right)$ represented the adsorption capacity when the adsorbate equilibrium concentration was equal to 1 , and $n$ expressed the degree of dependence of adsorption with equilibrium concentration.

Langmuir and Freundlich isotherms parameters for $\mathrm{Co}(\mathrm{II})$ and U(VI) adsorption on ACPCs were shown in Table 3. Higher correlation coefficients were observed for the Freundlich model than that of the Langmuir mode, suggesting multiple adsorption sites on the ACPCs surfaces to achieve adsorption process.

Thermodynamic parameters $\left(\Delta \mathrm{G}^{\circ}, \Delta \mathrm{S}^{\circ}\right.$ and $\left.\Delta \mathrm{H}^{\circ}\right)$ of the $\mathrm{Co}(\mathrm{II})$ and $\mathrm{U}(\mathrm{VI})$ adsorption on ACPCs calculated from isotherms on three different temperature, were investigated to determine whether the adsorption process occurred spontaneously. The value of the Gibbs free energy change $\left(\Delta \mathrm{G}^{\circ}\right)$ could be achieved by the following equation $^{52}$ :

$$
\Delta H^{0}=\Delta G^{0}+T \Delta S^{0}
$$




\begin{tabular}{|c|c|c|c|c|c|c|c|}
\hline \multirow[b]{2}{*}{ M } & \multirow[b]{2}{*}{$\mathbf{T}(\mathbf{K})$} & \multicolumn{3}{|c|}{ Langmuir model } & \multicolumn{3}{|c|}{ Freundlich model } \\
\hline & & $q_{\max }(m g / g)$ & $b(L / g)$ & $\mathbf{R}^{2}$ & $K_{F}\left(m g^{I-n} L^{n} / g\right)$ & $\mathbf{n}$ & $\mathbf{R}^{2}$ \\
\hline \multirow{4}{*}{$\mathrm{Co}(\mathrm{II})$} & 303 & 110.17 & 0.032 & 0.93 & 6.21 & 0.76 & 0.95 \\
\hline & 313 & 121.85 & 0.06 & 0.94 & 9.80 & 0.65 & 0.95 \\
\hline & 323 & 152.25 & 0.10 & 0.98 & 14.5 & 0.56 & 0.96 \\
\hline & 303 & 71.85 & 0.02 & 0.94 & 2.82 & 0.73 & 0.95 \\
\hline \multirow{2}{*}{$\mathrm{U}(\mathrm{VI})$} & 313 & 116.82 & 0.18 & 0.95 & 26.99 & 0.43 & 0.96 \\
\hline & 323 & 204.09 & 0.27 & 0.98 & 67.19 & 0.32 & 0.97 \\
\hline
\end{tabular}

Table 3. Langmuir and Freundlich isotherms parameters for Co(II) and U(VI) adsorption on ACPCs.

\begin{tabular}{|c|c|c|c|c|}
\hline & $\mathbf{T}(\mathrm{K})$ & $\Delta G^{0}(\mathrm{~kJ} / \mathrm{mol})$ & $\Delta H^{0}(\mathrm{~kJ} / \mathrm{mol})$ & $\Delta S^{0}(\mathrm{~J} / \mathrm{mol} / \mathrm{K})$ \\
\hline \multirow{3}{*}{$\mathrm{Co}$ (II) } & 303 & -9.03 & \multirow{3}{*}{17.9} & \multirow{3}{*}{88.9} \\
\hline & 313 & -9.92 & & \\
\hline & 323 & -10.8 & & \\
\hline \multirow{3}{*}{$\mathrm{U}(\mathrm{VI})$} & 303 & -10.4 & \multirow{3}{*}{86.5} & \multirow{3}{*}{319.9} \\
\hline & 313 & -13.5 & & \\
\hline & 323 & -16.8 & & \\
\hline
\end{tabular}

Table 4. Thermodynamic parameters for the adsorption of Co(II) and U(VI) by ACPCs.

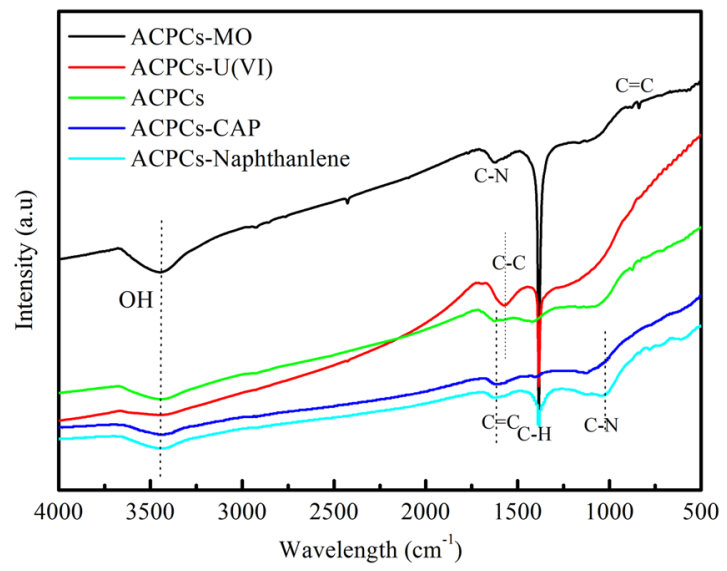

Figure 6. FTIR spectra of ACPCs after adsorption pollutants.

where $\mathrm{R}(8.314 \mathrm{~J} / \mathrm{mol} \mathrm{K})$ was the ideal gas constant and $\mathrm{T}$ was the temperature in Kelvin. The adsorption equilibrium constant $K_{0}$ can be calculated by plotting $\ln K_{\mathrm{d}}$ versus $C_{\mathrm{e}}$ and extrapolating $C_{\mathrm{e}}$ to zero.

The average standard enthalpy change $\left(\Delta H^{0}\right)$ and standard entropy change $\left(\Delta S^{0}\right)$ could be calculated from the slope and $y$-intercept to plot of $\ln K_{d}{ }^{0}$ versus $1 / \mathrm{T}$ (Fig. $5 \mathrm{E}$ and $\mathrm{F}$ ) using the Van't Hoff equation ${ }^{5,53}$ :

$$
\ln K_{\mathrm{d}}^{0}=\frac{\Delta S^{0}}{R}-\frac{\Delta H^{0}}{R T}
$$

where $K_{d}$ was the adsorption equilibrium constant. Table 4 listed $\Delta \mathrm{G}^{0}, \Delta \mathrm{S}^{0}$ and $\Delta \mathrm{H}^{0}$ calculated from the adsorption isotherms at three different temperatures. The adsorption process can be considered as a positive values of $\Delta H^{0}$ indicated an endothermic (positive values of $\Delta H^{0}$ ) and spontaneous (negative values of $\Delta G^{0}$ ) adsorption process.

Mechanism of Adsorption. FT-IR spectra were measured to investigate the adsorption mechanism (Fig. 6). One typical dye and ions were displayed here and others were shown in Figure S3. IR spectrum of all results showed peaks at $3450 \mathrm{~cm}^{-1}$ which can be assigned to the $\mathrm{O}-\mathrm{H}$ stretching vibration mode of hydroxyl functional groups. The obvious peaks around $1660-1550 \mathrm{~cm}^{-1}$ at ACPCs after adsorption heavy metal ions (Co(II)/U(VI)) and organic pollution because of the presence of highly conjugated C-O. An obvious peak at $2903 \mathrm{~cm}^{-1}$ after adsorption organic dyes (MB, MO and CR) clearly indicated the presence of aliphatic $\mathrm{C}-\mathrm{H}$ stretching from organic dyes ${ }^{54}$. Similarly, the overlapping bands in the region of $800-600 \mathrm{~cm}^{-1}$ after organic dye adsorption may 


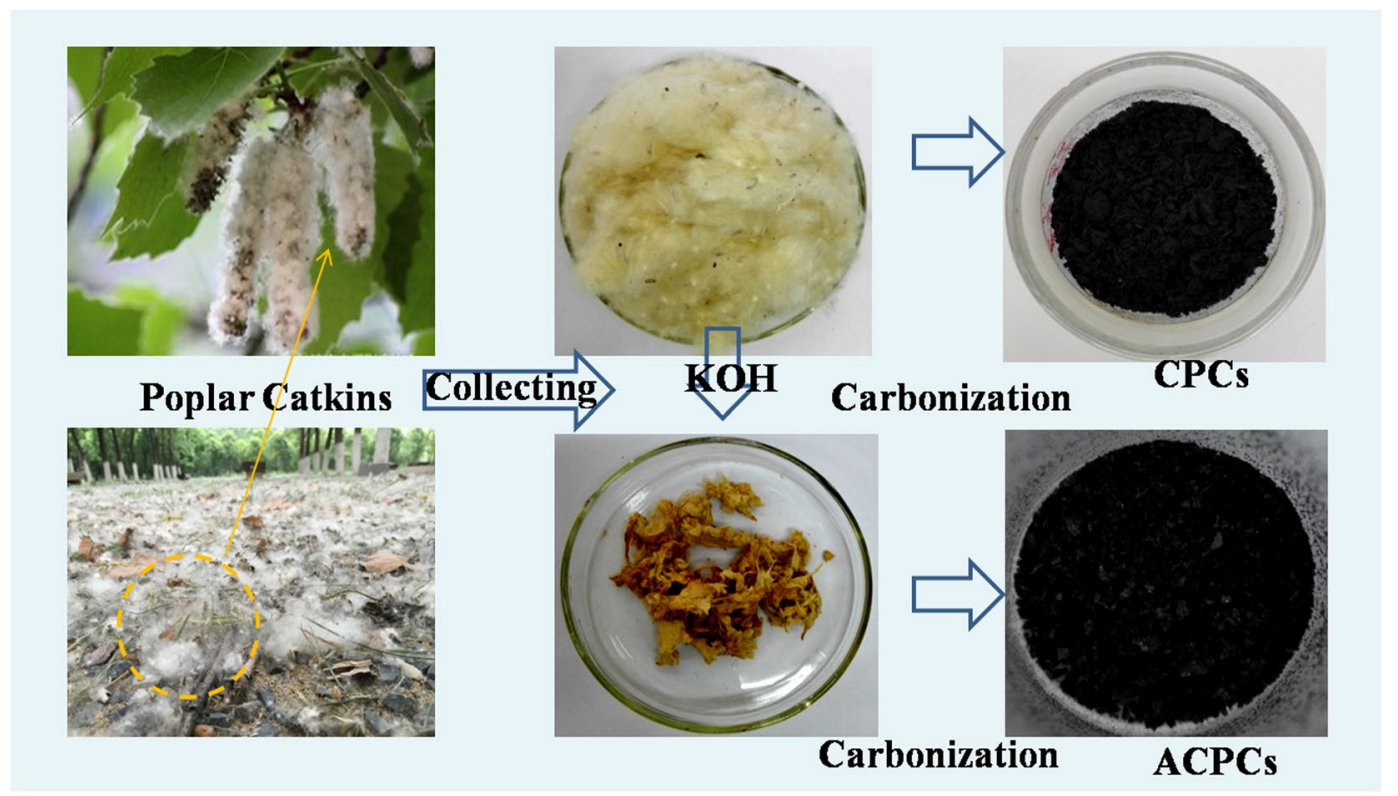

Figure 7. Detailed flow chart of the process for CPCs and ACPCs from poplar catkins.

be ascribed to the out of plane ring deformation of organic dyes ${ }^{55}$. The results clearly indicated chemisorption was in the process. In the region of $1030-1200 \mathrm{~cm}^{-1}$ after CAP and naphthalene adsorption may be C-N in CAP and naphthalene which indicated successfully sorbed CAP and naphthalene.

In conclusion, CPCs and ACPCs were successfully fabricated from poplar catkin. The prepared biochars exhibited good to excellent adsorption capacities for both organic pollutant (MB, MO, CR, CAP and naphthalene) and heavy metal ions (Co(II) and $\mathrm{U}(\mathrm{VI})$ ). The adsorption of $\mathrm{U}(\mathrm{VI})$ and $\mathrm{Co}(\mathrm{II})$ from aqueous solutions onto ACPCs were highly dependent on solution $\mathrm{pH}$ and ionic strength, indicating outer-sphere surface complexation dominated the adsorption mechanism. Thermodynamic studies indicated endothermic and spontaneous processes. Kinetic results showed that pseudo-second-order model was better fitted in the removal of dyes process. FT-IR results indicated the participation of the specific functional groups in adsorption interaction. The biochars derived from poplar catkins showed great potential in wastewater management in terms of their facile process, low cost and good ability of adsorption of heavy metals and organic pollution.

\section{Experimental Section}

Chemicals. Analytical pure reagent naphthalene and dyes were purchased from Sinopharm Chemical Reagent Co., Ltd. CAP was purchased from Aladdin Industrial Corporation (Shanghai, China). Properties of the organic pollutants adsorbates are listed in Table S4. The Co(II) and U(VI) stock solutions $(60 \mathrm{mg} / \mathrm{L})$ were prepared by dissolving their nitrate in Milli-Q water. The synthetic naphthalene aqueous solutions were prepared from a stock solution $(60 \mathrm{mg} / \mathrm{L})$ in ethanol (less than $5 \mathrm{wt}$. \%) by adequate dilution in Milli-Q water because of the low water solubility of naphthalene $(30 \mathrm{mg} / \mathrm{L})$.

Synthesis of adsorbents. The poplar catkins were collected in Shushan in Hefei, Anhui province in China (Fig. 7). The fabrication of CPCs and ACPCs were listed as follows: Specifically, $2.0 \mathrm{~g}$ of the collected poplar catkin was washed with deionized water to remove the impurity and dried at $70^{\circ} \mathrm{C}$ overnight. Half of dried poplar catkin $(\sim 1.0 \mathrm{~g})$ was dispersed in $40 \mathrm{~mL} 3.0 \mathrm{~mol} / \mathrm{L} \mathrm{KOH}$ solution with ultra-sonicating for $30 \mathrm{~min}$, and the mixture were dried at $65^{\circ} \mathrm{C}$ for $24 \mathrm{~h}$, followed by carbonization under nitrogen atmosphere by heating at $800^{\circ} \mathrm{C}$ for $1 \mathrm{~h}$ with a heating rate of $1^{\circ} \mathrm{C} \mathrm{min}{ }^{-1}$ to produced desired ACPCs. CPCs were obtained of the other half dried poplar catkin $(\sim 1.0 \mathrm{~g})$ by directly carbonization under same condition with ACPCs. The detailed fabrication process was schematically shown in Fig. 7. An optimization study aimed at identifying preferred conditions (carbonization/ activation) for preparing ACPCs was given in supporting information.

Characterization. SEM images were taken by a JEOL JSM-7001F microscope. TEM images were obtained using a JEOL-2010 transmission electron microscope with an accelerating voltage of $200 \mathrm{kV}$. XRD were taken on a Philips X'Pert X-ray diffractometer using $\mathrm{Cu} K \alpha$ radiation $(\lambda=0.15406 \mathrm{~nm})$. XPS spectra were obtained on an AXIS Ultra DLD spectrometer with an excitation source of $\mathrm{Mg} \mathrm{K \alpha}(1486.6 \mathrm{eV})$. FT-IR spectroscopy was performed using a Nicolet Magna-IR 750 spectrometer over a wave number range from 400 to $4000 \mathrm{~cm}^{-1}$. The zeta potentials were measured using a Zetasizer Nanosizer ZS instrument (Malvern Instrument Co., UK). Elemental composition was characterization by Vario EL cube, Elementar, Germany. Ash content of the samples was determined by combusting $0.5 \mathrm{~g}$ of adsorbent in a muffle furnace at $650^{\circ} \mathrm{C}$ for $2 \mathrm{~h}$.

Batch adsorption experiments. Adsorption experiments of heavy metal ions were performed in polyethylene test tubes and adsorption experiments of organic pollutants were conducted in $10 \mathrm{~mL}$ glass bottle by using 
batch experiment. The $\mathrm{pH}$ of the suspension in the range of 2.0-10.0 was adjusted by adding negligible amount of 0.1 or $0.01 \mathrm{~mol} / \mathrm{L} \mathrm{HNO}_{3}$ or $\mathrm{NaOH}$ solutions. The suspensions were then agitated on a shaker for a reaction time of $24 \mathrm{~h}$. The solid phase was separated from the solution phase by centrifugation at $8000 \mathrm{rpm}$ for $10 \mathrm{~min}$.

The concentrations of $\mathrm{Co}$ (II) were determined by a spectrophotometric method using Co(II)-Xylenol orange complex at the wavelength of $578 \mathrm{~nm}$ and the concentration of U(VI) was analyzed by the Dichlorophosphonoazo III spectrophotometer method at the wavelength of $669 \mathrm{~nm}$. The concentration of organic pollutant was analyzed by UV-vis (Shimadzu UV-2550) spectroscopy (the maximum absorption wavelength for every pollutant was shown in Table S3). The adsorption percentage (\%) and adsorption capacity $\left(q_{e}\right)$ which were achieved by the following equations $\mathrm{s}^{5,23}$

$$
\begin{gathered}
\text { Adsorption } \%=\frac{C_{0}-C_{e}}{C_{0}} \times 100 \% \\
q_{e}=\frac{C_{0}-C_{e}}{m} \times V
\end{gathered}
$$

where $C_{0}(\mathrm{mg} / \mathrm{L})$ is initial concentration and $C_{\mathrm{e}}(\mathrm{mg} / \mathrm{L})$ is final concentration of pollution in the aqueous phase, $\mathrm{m}(\mathrm{g})$ is mass of the adsorbent, and $\mathrm{V}(\mathrm{mL})$ is the volume adsorption solution. All the experimental data were the averages of duplicate determinations. Error bars represent standard deviation.

\section{References}

1. Chen, B. \& Chen, Z. Sorption of naphthalene and 1-naphthol by biochars of orange peels with different pyrolytic temperatures. Chemosphere 76, 127-133 (2009).

2. Islam, M. A. et al. Methylene blue adsorption on factory-rejected tea activated carbon prepared by conjunction of hydrothermal carbonization and sodium hydroxide activation processes. J. Taiwan Inst. Chem. Eng. 52, 57-64 (2015).

3. Yang, X. et al. Adsorption of naphthalene and its derivatives on magnetic graphene composites and the mechanism investigation. Colloid Surf. A-Physicochem. Eng. Asp. 422, 118-125 (2013).

4. Sylwester, E., Hudson, E. \& Allen, P. The structure of uranium (VI) sorption complexes on silica, alumina, and montmorillonite. Geochim. Cosmochim. Acta 64, 2431-2438 (2000).

5. Wu, P. et al. Removal of $\mathrm{Cd}^{2+}$ from aqueous solution by adsorption using Fe-montmorillonite. J. Hazard. Mater. 169, 824-830 (2009).

6. Kara, M., Yuzer, H., Sabah, E. \& Celik, M. Adsorption of cobalt from aqueous solutions onto sepiolite. Water Res. 37, 224-232 (2003).

7. Zhao, G., Li, J., Ren, X., Chen, C. \& Wang, X. Few-layered graphene oxide nanosheets as superior sorbents for heavy metal ion pollution management. Environ. Sci. Technol. 45, 10454-10462 (2011).

8. Sun, L., Chen, D., Wan, S. \& Yu, Z. Performance, kinetics, and equilibrium of methylene blue adsorption on biochar derived from eucalyptus saw dust modified with citric, tartaric, and acetic acids. Bioresour. Technol. 198, 300-308 (2015).

9. Jain, A. K., Gupta, V. K., Bhatnagar \& Suhas, A. Utilization of industrial waste products as adsorbents for the removal of dyes. J. Hazard. Mater. 101, 31-42 (2003).

10. Wang, X. \& Xing, B. Sorption of organic contaminants by biopolymer-derived chars. Environ. Sci. Technol. 41, 8342-8348 (2007).

11. Zhu, D., Kwon, S. \& Pignatello, J. J. Adsorption of single-ring organic compounds to wood charcoals prepared under different thermochemical conditions. Environ. Sci. Technol. 39, 3990-3998 (2005).

12. Bailey, S. E., Olin, T. J., Bricka, R. M. \& Adrian, D. D. A review of potentially low-cost sorbents for heavy metals. Water Res. 33, 2469-2479 (1999).

13. Jiang, J., Xu, R., Jiang, T. \& Li, Z. Immobilization of $\mathrm{Cu}(\mathrm{II}), \mathrm{Pb}(\mathrm{II})$ and $\mathrm{Cd}(\mathrm{II})$ by the addition of rice straw derived biochar to a simulated polluted Ultisol. J. Hazard. Mater. 230, 145-150 (2012).

14. Kılıç, M., Kırbıyık, Ç., Çepelioğullar, Ö. \& Pütün, A. E. Adsorption of heavy metal ions from aqueous solutions by bio-char, a byproduct of pyrolysis. Appl. Surf. Sci. 283, 856-862 (2013).

15. Mohan, D., Sarswat, A., Ok, Y. S. \& Pittman, C. U. Jr. Organic and inorganic contaminants removal from water with biochar, a renewable, low cost and sustainable adsorbent. Bioresour. Technol. 160, 191-202 (2014).

16. Angin, D. Utilization of activated carbon produced from fruit juice industry solid waste for the adsorption of Yellow 18 from aqueous solution. Bioresour. Technol. 168, 259-266 (2014).

17. Annadurai, G., Juang, R. S. \& Lee, D. J. Use of cellulose-based wastes for adsorption of dyes from aqueous solutions. J. Hazard. Mater. 92, 263-274 (2002).

18. Huang, S. \& Shi, J. Monolithic macroporous carbon materials as high-performance and ultralow-cost sorbents for efficiently solving organic pollution. Ind. Eng. Chem. Res. 53, 4888-4893 (2014).

19. Chen, X. G. et al. Adsorption of methylene blue by rice hull ash. Sep. Sci. Technol. 47, 147-156 (2012).

20. Zeng, D. H., Mao, R., Chang, S. X., Li, L. Z. \& Yang, D. Carbon mineralization of tree leaf litter and crop residues from poplar-based agroforestry systems in Northeast China. Appl. Soil Ecol. 44, 133-137 (2010).

21. Xie, L. et al. Hierarchical porous carbon microtubes derived from willow catkins for supercapacitor applications. J. Mater. Chem. A 4, 1637-1646 (2016).

22. Mohamed, R. et al. Populus CEN/TFL1 regulates first onset of flowering, axillary meristem identity and dormancy release in populous. Plant J. 62, 674-688 (2010).

23. Wei, Y. et al. Activated carbon microtubes prepared from plant biomass (poplar catkins) and their application for supercapacitors. Chem. lett. 43, 216-218 (2014).

24. Zhang, Y., Zhao, Y., Konarov, A., Li, Z. \& Chen, P. Effect of mesoporous carbon microtube prepared by carbonizing the poplar catkin on sulfur cathode performance in Li/S batteries. J. Alloy. Compd. 619, 298-302 (2015).

25. Zhang, S. et al. Porous magnetic carbon sheets from biomass as an adsorbent for the fast removal of organic pollutants from aqueous solution. J. Mater. Chem. A 2, 4391-4397 (2014).

26. Song, S. et al. Facile self-templating large scale preparation of biomass-derived 3D hierarchical porous carbon for advanced supercapacitors. J. Mater. Chem. A 3, 18154-18162 (2015).

27. Chen, L. et al. Flexible all-solid-state high-power super capacitor fabricated with nitrogen-doped carbon nanofiber electrode material derived from bacterial cellulose. Energy Environ. Sci. 6, 3331-3338 (2013).

28. Teixeira, E. et al. Cellulose nanofibers from white and naturally colored cotton fibers. Cellulose 17, 595-606 (2010).

29. Qie, L. et al. Synthesis of functionalized 3D hierarchical porous carbon for high-performance supercapacitors. Energy Environ. Sci. 6, 2497-2504 (2013).

30. Shchukarev, A., Sundberg, B., Mellerowicz, E. \& Persson, P. XPS study of living tree. Surf. Interface Anal. 34, 284-288 (2002). 
31. Chen, H., Wang, X. X., Li, J. X. \& Wang, X. K. Cotton derived carbonaceous aerogels for the efficient removal of organic pollutants and heavy metal ions. J. Mater. Chem. A 3, 6073-6081 (2015).

32. Nikolaos, P. \& Constantinos, V. Interaction between graphene oxide nanoparticles and quartz sand. Environ. Sci. Technol. 49, 13413-13421 (2015).

33. Yao, Y. et al. Biochar derived from anaerobically digested sugar beet tailings: Characterization and phosphate removal potential. Bioresour. Technol. 102, 6273-6278 (2012).

34. $\mathrm{Bi}, \mathrm{H}$. et al. Spongy graphene as a highly efficient and recyclable sorbent for oils and organic solvents. Adv. Funct. Mater. 22, $4421-4425$ (2012).

35. Li, Y. et al. Comparative study of methylene blue dye adsorption onto activated carbon, graphene oxide, and carbon nanotubes. Chem. Eng. Res. Des. 91, 361-368 (2013).

36. Aygün, A., Yenisoy-Karakaş, S. \& Duman, I. Production of granular activated carbon from fruit stones and nutshells and evaluation of their physical, chemical and adsorption properties. Microporous Mesoporous Mat. 66, 189-195 (2003).

37. Ghosh, R. \& Reddy, D. Tobacco stem ash as an adsorbent for removal of methylene blue from aqueous solution: equilibrium, kinetics, and mechanism of adsorption. Water Air Soil Pollut. 224, 1-12 (2013).

38. Sven, S. K. L. About the theory of so-called adsorption of soluble substances. Vetenskapsakad. Handl. 24, 1-39 (1898).

39. Ho, Y. S. \& McKay, G. Sorption of dye from aqueous solution by peat. Chem. Eng. J. 70, 115-124 (1998).

40. Weber, W. J. Jr. \& Morris, J. C. Kinetics of adsorption on carbon from solution. J. Sanit. Eng. Div. Am. Soc. Civil Eng. 89, 31-60 (1963).

41. Jin, X. et al. Preparation of novel nano-adsorbent based on organic-inorganic hybrid and their adsorption for heavy metals and organic pollutants presented in water environment. J. Hazard. Mater. 186, 1672-1680 (2011).

42. Long, C. et al. Adsorption of naphthalene onto the carbon adsorbent from waste ion exchange resin: equilibrium and kinetic characteristics. J. Hazard. Mater. 150, 656-661 (2008).

43. Oday, P., ChisholmBrause, C., Towle, S., Parks, G. \& Brown, G. X-ray absorption spectroscopy of Co(II) sorption complexes on quartz (alpha- $\left.\mathrm{SiO}_{2}\right)$ and rutile $\left(\mathrm{TiO}_{2}\right)$. Geochim. Cosmochim. Acta 60, 2515-2532 (1996).

44. Fang, F. et al. Removal of cobalt ions from aqueous solution by an amination graphene oxide nanocomposite. J. Hazard. Mater. 270, $1-10$ (2014).

45. Zou, Y. et al. Environmental remediation and application of nanoscale zero-valent iron and its composites for the removal of heavy metal ions: a review. Environ. Sci. Technol. 50, 7290-7304 (2016).

46. Yuezer, H., Kara, M., Sabah, E. \& Celikc, M. Contribution of cobalt ion precipitation to adsorption in ion exchange dominant systems. J. Hazard. Mater. 151, 33-37 (2008).

47. Zou, Y. et al. Superior coagulation of graphene oxides on nanoscale layered double hydroxides and layered double oxides. Environ. Pollut. 219, 107-117 (2016).

48. Sun, Y. et al. Macroscopic and microscopic investigation of U (VI) and Eu (III) adsorption on carbonaceous nanofibers. Environ. Sci. Technol. 50, 4459-4467 (2016).

49. Liu, X., Li, J. X., Wang, X. X., Chen, C. L. \& Wang, X. K. High performance of phosphate-functionalized graphene oxide for the selective adsorption of U(VI) from acidic solution. J. Nucl. Mater. 466, 56-64 (2015).

50. Zhang, W. et al. Adsorption of anionic dyes from aqueous solutions using chemically modified straw. Bioresour. Technol. 117, 40-47 (2012).

51. Chaukura, N. et al. Conversion of post consumer waste polystyrene into a high value adsorbent and its sorptive properties for Congo Red removal from aqueous solution. J. Environ. Manag. 193, 280-289 (2017).

52. Freundlich, H. Über die adsorption in lösungen. Zeitschrift für Physikalische (1906).

53. Chen, H., Shao, D., Li, J., Alsaedi, A. \& Wang, X. The uptake of radionuclides from aqueous solution by poly (amidoxime) modified reduced graphene oxide. Chem. Eng. J. 254, 623-634 (2014).

54. Namasivayam, C. \& Kavitha, D. IR, XRD and SEM studies on the mechanism of adsorption of dyes and phenols by coir pith carbon from aqueous phase. Microchem J. 82, 43-48 (2006).

55. Yamaguchi, D. et al. Hydrolysis of cellulose by a solid acid catalyst under optimal reaction conditions. J. Phys. Chem. C 113, 3181-3188 (2009).

56. Liao, P. et al. Adsorption of tetracycline and chloramphenicol in aqueous solutions by bamboo charcoal: A batch and fixed-bed column study. Chem. Eng. J. 228, 496-505 (2013).

57. Mahtab, A. et al. Effects of pyrolysis temperature on soybean stover- and peanut shell-derived biochar properties and TCE adsorption in water. Bioresour. Technol. 118, 536-544 (2012).

58. Belen, C. et al. Adsorption of naphthalene from aqueous solution on activated carbons obtained from bean pods. J. Hazard. Mater. 161, 1150-1156 (2009).

59. Pang, C. et al. Biosorption of uranium(VI) from aqueous solution by dead fungal biomass of Penicillium citrinum. Chem. Eng. J. 145, 489-495 (2009)

60. Tan, X., Liu, Y. \& Zeng, G. Application of biochar for the removal of pollutants from aqueous solutions. Chemosphere 125, 70-85 (2015).

61. Vijayaraghavan, K., Jegan, J., Palanivelu, K. \& Velan, M. Biosorption of cobalt (II) and nickel(II) by seaweeds: batch and column studies. Sep. Purif. Technol. 44, 53-59 (2005).

62. Kausar, A., Bhatti, H. N. \& MacKinnon, G. Equilibrium, kinetic and thermodynamic studies on the removal of U(VI) by low cost agricultural waste. Colloids Sur. B 111, 124-133 (2013).

\section{Acknowledgements}

The authors acknowledge the financial support provided by National Natural Science Foundation of China (21677146), special scientific research fund of public welfare profession of China (201509074), the Chinese National Fusion Project for ITER (2013GB110005) and Jiangsu Provincial Key Laboratory of Radiation Medicine and Protection and the Priority Academic Program Development of Jiangsu Higher Education Institutions.

\section{Author Contributions}

X.L. and J.X.L. conceived and designed the experiments. X.L. analyzed the data and wrote the paper. X.L. and J.S. performed the experiments. Y.N.W., T.H. and A.A. participated in the discussions. C.M.W. prepared Figure 6. J.X.L. and S.X.D. helped with experiments and provided valuable suggestions.

\section{Additional Information}

Supplementary information accompanies this paper at doi:10.1038/s41598-017-09446-0

Competing Interests: The authors declare that they have no competing interests.

Publisher's note: Springer Nature remains neutral with regard to jurisdictional claims in published maps and institutional affiliations. 
(i) Open Access This article is licensed under a Creative Commons Attribution 4.0 International License, which permits use, sharing, adaptation, distribution and reproduction in any medium or format, as long as you give appropriate credit to the original author(s) and the source, provide a link to the Creative Commons license, and indicate if changes were made. The images or other third party material in this article are included in the article's Creative Commons license, unless indicated otherwise in a credit line to the material. If material is not included in the article's Creative Commons license and your intended use is not permitted by statutory regulation or exceeds the permitted use, you will need to obtain permission directly from the copyright holder. To view a copy of this license, visit http://creativecommons.org/licenses/by/4.0/.

(C) The Author(s) 2017 